\title{
Toxigenic Capacity and Trichothecene Production by Fusarium graminearum Isolates from Argentina and Their Relationship with Aggressiveness and Fungal Expansion in the Wheat Spike
}

\author{
I. Malbrán, C. A. Mourelos, J. R. Girotti, P. A. Balatti, and G. A. Lori
}

First, second, fourth, and fifth authors: Centro de Investigaciones de Fitopatología (CIDEFI), Facultad de Ciencias Agrarias y Forestales, Universidad Nacional de La Plata, 60 y 119, CC 31, (1900) La Plata, Buenos Aires, Argentina; and third author: Instituto de Investigaciones Bioquímicas de La Plata (INIBIOLP) (CCT CONICET La Plata), Facultad de Ciencias Médicas, Universidad Nacional de La Plata, 60 y 120, (1900) La Plata, Buenos Aires, Argentina.

Accepted for publication 18 October 2013.

\begin{abstract}
Malbrán, I., Mourelos, C. A., Girotti, J. R., Balatti, P. A., and Lori, G. A. 2014. Toxigenic capacity and trichothecene production by Fusarium graminearum isolates from Argentina and their relationship with aggressiveness and fungal expansion in the wheat spike. Phytopathology 104:357-364.

At least 20 epidemics of Fusarium head blight (FHB) of wheat have been registered in the last 50 years in Argentina, with variable intensity. Damage induced by the disease is further aggravated by the presence of mycotoxins in affected grains that may cause health problems to humans and animals. The trichothecene chemotype was analyzed for 112 isolates of Fusarium graminearum from Argentina by polymerase chain reaction

subsample of 14 representative isolates and to analyze deoxynivalenol (DON) production in planta and in vitro. All isolates belonged to the 15acetyl-DON chemotype. Significant differences were observed in both the symptom severity induced in wheat spikes and the in vivo DON production, and a close correlation was found between these two variables. However, in vitro toxigenic potential was not correlated with the capacity of $F$. graminearum isolates to produce DON under natural conditions. The progress of infection in the rachis of inoculated wheat spikes was analyzed and the pathogen presence verified in both symptomatic and symptomless spikes. Even isolates with a limited capacity to induce symptoms were able to colonize the vascular tissue and to produce considerable amounts of DON in planta.
\end{abstract} and two field trials were conducted to study the aggressiveness of a
Fusarium head blight (FHB) of wheat, caused by Fusarium graminearum (Schwabe), is a destructive disease that frequently causes epidemics in many wheat-cropping areas worldwide $(15,38)$. In Argentina, at least 20 epidemics have been registered in the last 50 years with variable intensity, the more severe occurring in 1945-46, 1976, 1978, 1985, 1993, and 2001 $(19,28,43)$.

The disease affects several major crops, including maize, wheat, barley, rye, and triticale, reducing seed and grain quality as well as yield, leading to poor germination and reduction in flour baking properties. The damages induced by the disease are further aggravated by the frequent presence of mycotoxins in affected grains. These persistent, thermostabile metabolites, produced in association with food and feeds, may cause health problems to humans and animals even in low doses (27).

The trichothecenes deoxynivalenol (DON) and its derivatives 3acetyl-DON (3-ADON) and 15-acetyl-DON (15-ADON), and nivalenol (NIV) and its acetylate derivative Fusarenone X (FUS$\mathrm{X}$ ), are the major mycotoxins produced by $F$. graminearum (36). DON, the most important mycotoxin in terms of human exposition (42), has been found as a contaminant of wheat, maize, and barley, three crops that account for two-thirds of the worldwide production of cereals.

\section{Corresponding author: I. Malbrán; E-mail address: imalbran@yahoo.com.ar}

* The $\boldsymbol{e}$-Xtra logo stands for "electronic extra" and indicates that Figure 1 appears in color online.

http://dx.doi.org/10.1094/PHYTO-06-13-0172-R

(c) 2014 The American Phytopathological Society
Trichothecenes are synthesized by a complex metabolic route that involves a series of oxygenations, isomerizations, and esterifications (3). According to the pattern of trichothecene production, isolates of $F$. graminearum can be organized into three different chemotypes: $I a$, producing DON and 3-ADON; $I b$, producing DON and 15-ADON; and II, producing NIV and FUS$\mathrm{X}(24,44)$. Most of the genes involved in the biosynthesis of trichothecenes and, thus, in its variations, are localized in a cluster of at least 10 genes (8) that encode regulatory proteins as well as most of the enzymes required for trichothecene synthesis (3). Among them, Tril3 and Tri7 are responsible for the production of DON- or NIV-like trichothecenes (30), while differences in the sequence of Tri8 have been identified as the basis for the production of either 3-ADON or 15-ADON (2). The identification of these genes provided the basis for the development of valuable polymerase chain reaction (PCR) tools for fast chemotype determination in $F$. graminearum $(58,63)$.

Differences in the geographic distribution of $F$. graminearum chemotypes have been reported. In Chinese populations of the pathogen, DON-like chemotypes prevail, with similar frequencies of 15-ADON and 3-ADON strains (65); whereas, in Japan, the prevalent chemotype is NIV (59). In Europe, 15-ADON is the most frequent chemotype, followed by 3 -ADON and only a few representatives of NIV strains $(26,47,51)$. In the United States and Canada, where 15-ADON was previously identified as the predominant chemotype, increasing frequencies of 3-ADON and NIV strains have been recently reported $(52,58)$. In Brazil and Uruguay, 15-ADON is the most commonly found trichothecene chemotype, with only sporadic recovery of strains of NIV chemotype $(7,46)$. 
Controversy exists regarding the chemotype composition of $F$. graminearum populations from Argentina. Several authors reported the prevalence of DON chemotypes in the wheat-cropping area $(4,10,16,54)$, while others also reported the presence of NIV chemotypes $(18,33,55,57)$. These antecedents suggest that, even when DON seems to be the predominant chemotype in F. graminearum isolates from Argentina, the potential exists for the occurrence of grain contamination with NIV.

Qualitative and quantitative differences in the synthesis of enzymes and mycotoxins might be responsible for the great variability in aggressiveness observed within $F$. graminearum populations (41). The phytotoxic activity of trichothecenes, and particularly of DON, has been widely studied. On plant tissue, these compounds inhibit protein synthesis and mitochondrial function and affect cell division and membranes (56). Reduced production of trichothecenes does not influence the capacity of $F$. graminearum to infect wheat or maize but affects the progression of the infection due to a decrease in aggressiveness $(49,50)$. However, the mechanism by which these metabolites induce the development of FHB remains largely unclear. It has been proposed that, during disease spread, trichothecenes could be translocated in the plant before the growth of the pathogen, reducing protein synthesis without inducing the activation of defense mechanisms $(45,48)$. Furthermore, trichothecenes have been found to inhibit the development of defense mechanisms in the wheat rachis node that would otherwise prevent the movement of the fungus into the internode (25). On the other hand, evidence has been found that DON may activate a range of plant defense responses and programmed cell death in wheat, simultaneously favoring necrotrophic growth of the pathogen and stimulating antimicrobial defense responses in the host (14).

A correlation between aggressiveness and DON production has been proposed for $F$. graminearum and $F$. culmorum $(13,62)$. McCormick (36) suggested that the role of trichothecenes as aggressiveness factors highlights the possibility of developing wheat cultivars resistant to the accumulation of mycotoxins that could improve plant response to the disease. However, experiments on wheat have yielded controversial results and several authors have either failed to find a significant correlation between FHB and production of trichothecenes or found inconsistent results $(1,6,32,61)$.

In Argentina, a high level of variability in the aggressiveness of $F$. graminearum was found within isolates from wheat $(5,35)$. Alvarez et al. (5) carried out specific assays but were unable to establish the relationship between FHB symptoms on wheat spikes, toxigenic capacity of $F$. graminearum isolates, and progression of the pathogen on wheat tissue.

Therefore, the clarification of chemotype distribution and of the relationship between mycotoxin accumulation and aggressiveness of isolates of $F$. graminearum from Argentina remains an issue of great importance, because it could greatly help the development of wheat genotypes tolerant or resistant to FHB. With this in mind, the objectives of the present work were to (i) identify the mycotoxin chemotypes of $F$. graminearum isolates from the
Buenos Aires Province in Argentina, (ii) quantify their toxigenic capacity, and (iii) correlate the accumulation of trichothecenes in wheat grains with aggressiveness of the pathogen and its capacity to colonize the spike.

\section{MATERIALS AND METHODS}

F. graminearum chemotype analysis. Chemotype analysis were carried out on $112 \mathrm{~F}$. graminearum isolates obtained from grain samples of common wheat (Triticum aestivum L.) collected from 28 different localities distributed within Buenos Aires Province, Argentina (35). Isolate chemotypes were determined by means of the two multiplex PCRs developed by Starkey et al. (58) using the chemotype-specific primers previously validated by Ward et al. (63). The sequence of the primers used, target genes, and amplified products are detailed in Table 1.

Both multiplex-PCRs were carried out in a $25-\mu l$ volume containing 5 to $10 \mathrm{ng}$ of genomic DNA, $1 \mathrm{U}$ of T-plus DNA polymerase (Highway Molecular Biology-InBio-UNICEN, Tandil, Argentina), $0.5 \mu \mathrm{M}$ each primer (FAGOS/Ruralex, Buenos Aires, Argentina), $200 \mu \mathrm{M}$ each deoxynucleoside triphosphate, and $1.5 \mathrm{mM} \mathrm{MgCl}_{2}$ in $1 \times$ reaction buffer $(500 \mathrm{mM} \mathrm{KCl}, 100 \mathrm{mM}$ Tris$\mathrm{Cl}$ [pH 9.0], and $1 \%$ Triton $\mathrm{X}-100$ without $\mathrm{Mg}^{++}$). Both PCR cycles consisted of an initial denaturation step of 3 min at $94^{\circ} \mathrm{C}$; followed by 35 cycles of $30 \mathrm{~s}$ at $94^{\circ} \mathrm{C}, 30 \mathrm{~s}$ at $53^{\circ} \mathrm{C}$, and $1 \mathrm{~min}$ at $72^{\circ} \mathrm{C}$; and a final extension step of $10 \mathrm{~min}$ at $72^{\circ} \mathrm{C}$. Amplification products were resolved on $1.5 \%$ (wt/vol) agarose gels containing ethidium bromide at $0.2 \mathrm{mg} \mathrm{ml}^{-1}$ in Tris-borate-EDTA buffer. Gels were visualized under UV using a GeneGenius (Syngene, Frederick, USA) image analyzer. Photos were taken with GeneSnaps software and the size of the resulting fragments was estimated using GeneTools and GeneDirectory software by comparison with the bands generated by a 1-kb DNA ladder (Highway Molecular Biology-InBio-UNICEN). In each of the amplification reactions, a negative control without DNA and positives controls for each chemotype were included.

Evaluation of the aggressiveness of $\boldsymbol{F}$. graminearum isolates. Two field trials were conducted in consecutive years to evaluate aggressiveness of the 112 isolates of $F$. graminearum using common wheat 'Klein Chajá' (35). In both trials, 20 field-grown wheat spikes were point inoculated with each isolate at anthesis (Zadoks growth stage 65) (64) in a completely randomized block design with four replicates, each consisting of five spikes.

Spikes were visually rated for disease severity 21 days postinoculation (dpi), considering symptomatic spikelets for each spike above and below the point of inoculation (PI). Disease severity, thousand-kernel weight (TKW), and area under the disease progress curve (AUDPC) differences between isolates, as well as the correlations found between these parameters, are reported elsewhere (35). The spikes inoculated with 14 isolates were selected to further evaluate infection progress along the rachis and mycotoxin production. These isolates were selected because they reflected the variability present among the aggressiveness groups constructed with the results obtained from the field tests (35).

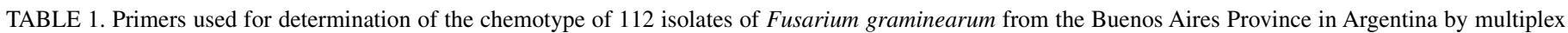
polymerase chain reaction

\begin{tabular}{|c|c|c|c|c|}
\hline Primer & Sequence $\left(5^{\prime}-3^{\prime}\right)$ & Chemotype $^{z}$ & Target gene & Amplified product (bp) \\
\hline 3NA & GTG CAC AGA ATA TAC GAG C & NIV & TRI3 & 840 \\
\hline 3D15A & ACT GAC CCA AGC TGC CAT C & 15-ADON & $\ldots$ & 610 \\
\hline 3D3A & CGC ATT GGC TAA CAC ATG & 3-ADON & $\ldots$ & 243 \\
\hline $3 \mathrm{CON}$ & TGG CAA AGA CTG GTT CAC & $\ldots$ & $\ldots$ & $\ldots$ \\
\hline $12 \mathrm{NF}$ & TCT CCT CGT TGT ATC TGG & NIV & TRII2 & 840 \\
\hline $12-15 \mathrm{~F}$ & TAC AGC GGT CGC AAC TTC & 15-ADON & $\ldots$ & 670 \\
\hline $12-3 \mathrm{~F}$ & CTT TGG CAA GCC CGT GCA & 3-ADON & $\ldots$ & 410 \\
\hline $12 \mathrm{CON}$ & CAT GAG CAT GGT GAT GTC & $\ldots$ & $\ldots$ & $\ldots$ \\
\hline
\end{tabular}

${ }^{\mathrm{z}} \mathrm{NIV}=$ nivalenol and 15 - and 3-ADON $=15$ - and 3-acetyl-deoxynivalenol, respectively. 
Analysis of the wheat spike colonization. At maturity, the wheat spikes inoculated with each of the 14 selected F. graminearum isolates in each of the two field tests were hand threshed. The grain was saved for TKW and mycotoxin determinations while the resulting rachis were superficially disinfected by dipping in $70^{\circ}$ ethanol for $1 \mathrm{~min}$ and in a $5 \%$ commercial $\mathrm{NaClO}$ solution $\left(\mathrm{Cl}\right.$ at $\left.55 \mathrm{~g} \mathrm{liter}^{-1}\right)$ for $1 \mathrm{~min}$, followed by rinsing in distilled water for $5 \mathrm{~min}$. Surface-sterilized rachis were cut, so that each of the resulting fragments consisted of a rachis node and the adjacent internode, and plated on $2 \%(\mathrm{wt} / \mathrm{vol})$ potato dextrose agar medium (PDA) supplemented with chloramphenicol at 250 $\mathrm{mg} \mathrm{liter}{ }^{-1}$ and pentachloronitrobenzene $(75 \%$ wettable powder) at $600 \mathrm{mg} \mathrm{liter}^{-1}$. Fragments were numbered with positive or negative successive numbers according to their relative position from the PI and the disposition of the fragments of the rachis in the spike was taken into consideration when plating (Fig. 1). The rachis of the control treatments of the field tests were used as a control.

After 5 days of incubation at $25 \pm 2{ }^{\circ} \mathrm{C}$, expansion in the rachis was evaluated as the percentage of rachis fragments colonized by $F$. graminearum. To avoid false positives, infection of the fragments by $F$. graminearum was confirmed by two complementary approaches: microscopic observation of the colonies obtained on PDA and of the macroconidia obtained in carnation leaves agar or PCR analysis by using primers FG16N F and FG16N R, as previously reported (35).

In vivo and in vitro DON production. In vivo and in vitro DON productions were evaluated for the 14 isolates of $F$. graminearum tested for pathogen expansion along the rachis. Toxin was quantified by means of the RIDASCREEN FAST DON (RBiopharm, Germany) enzyme-linked immunosorbent assay (ELISA) kit, according to the manufacturer's instructions $(22,23)$. For in vivo DON production analysis, the grains obtained from the field-test-inoculated spikes were ground, weighed, and used for quantification. The grains obtained from field test control spikes were considered to be negative controls.

For in vitro DON quantification, the $14 \mathrm{~F}$. graminearum isolates were cultivated in triplicate in 250-ml Erlenmeyer flasks containing $25 \mathrm{~g}$ of polished rice and $20 \mathrm{~g}$ of distilled water $(80 \%$ humidity). Previously autoclaved substrate was inoculated with a 5-mm-diameter plug of a 7-day-old $F$. graminearum colony grown on PDA. As a negative control, three Erlenmeyer flasks containing the rice substrate were inoculated with a 5-mmdiameter plug of autoclaved PDA. Flasks were cultivated for
28 days at $25 \pm 2{ }^{\circ} \mathrm{C}$ in the dark, dried in a stove with forced-air circulation until constant weight, ground, and weighed.

For DON quantification, the full amount of the ground $F$. graminearum-contaminated grain from each inoculated block of both field trials was used for in vivo production while all the rice substrate from each Erlenmeyer flask was used for in vitro production. Ground material was diluted 1:20 (wt/vol) in distilled water and homogenized in a magnetic stirrer for $3 \mathrm{~min}$, the extract obtained was filtered through Whatman number 1 filter paper, and a 50- $\mu$ l aliquot was pipetted into each well of the ELISA plate for the analysis. Absorbance was measured in a Beckman Coulter dtx-800 multimode detector (Beckman Coulter, Brea, USA) at $450 \mathrm{~nm}$ and data were converted to DON concentration by means of the RIDASOFT Win software using the standard curve obtained from the DON standards provided in the kit.

Statistical analysis. Data taken as percentage were arcsinetransformed prior to analysis. Aggressiveness, trichothecene production, and expansion of $F$. graminearum along the spike were analyzed by analysis of variance and means were compared using Tukey's test $(P \leq 0.05)$. Correlations were carried out for all combinations of parameters at $\alpha=0.05$. For in vivo DON production, TKW, and premature bleaching of the spike, data were collected using blocks as experimental units. All the analyses were performed using Statistix v.8.

A combined analysis model (37) was applied to the disease severity at $21 \mathrm{dpi}$, phenotypic variance components were estimated from the expected mean squares, and broad-sense heritability was calculated using the formula by Fehr (17), as previously reported (35).

\section{RESULTS}

Chemotype analysis of $\boldsymbol{F}$. graminearum isolates. All 112 F. graminearum isolates obtained from 28 localities in Argentina belonged to the 15-ADON chemotype according to the size of the fragments amplified by both multiplex PCR protocols (58).

Selection of isolates for the evaluation of the expansion of $F$. graminearum in the spike, in vivo, and in vitro DON production. The 14 isolates selected were tested to check that this subsample reflected the results previously obtained (35). To do so, the analysis of severity $21 \mathrm{dpi}$, TKW reduction, and heritability according to Fehr (17) carried out for the greater group of isolates were repeated.

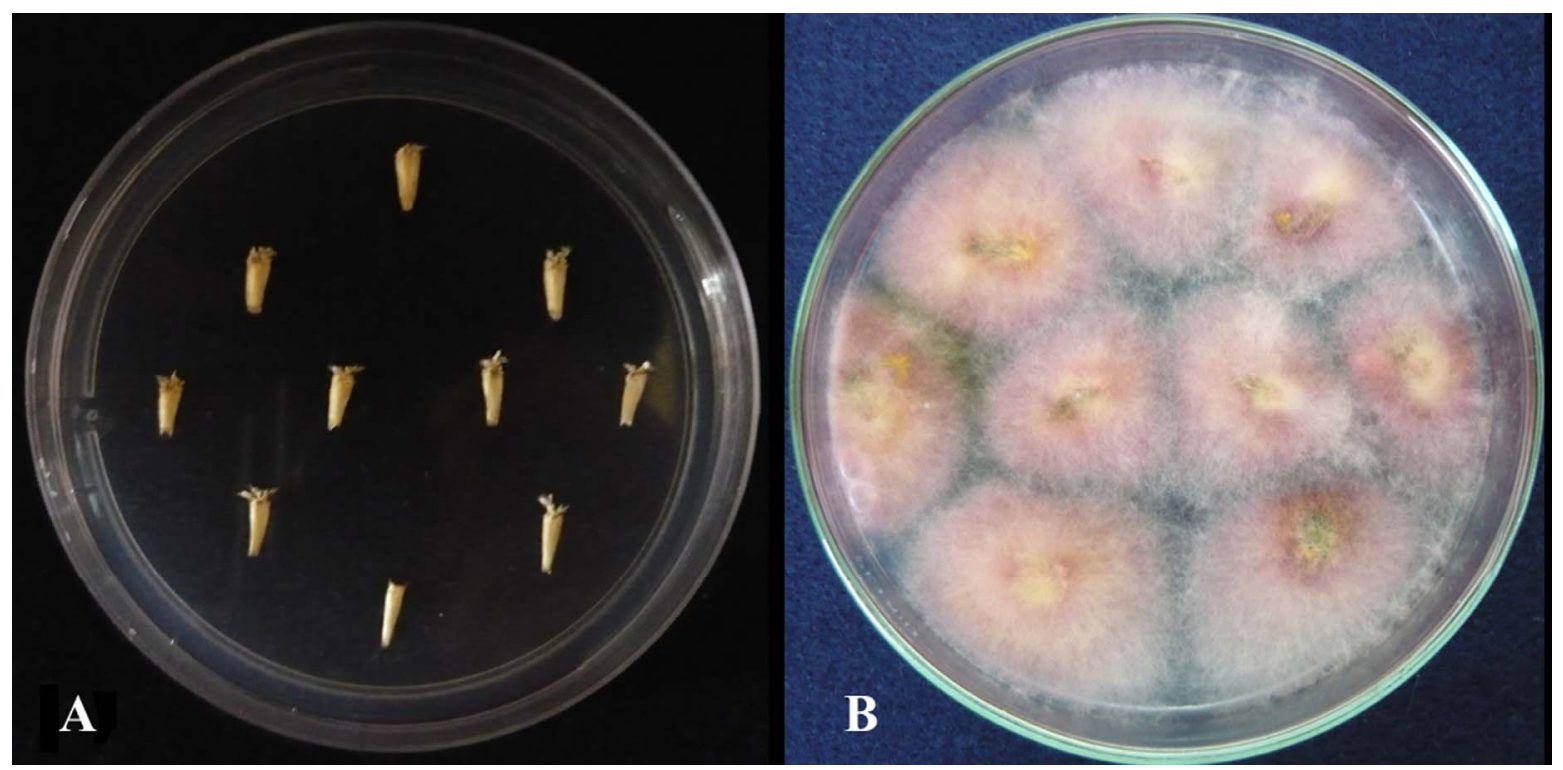

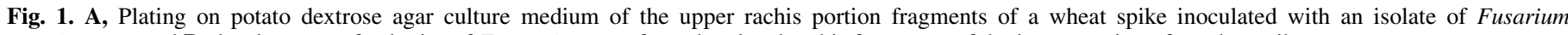
graminearum and $\mathbf{B}$, development of colonies of $F$. graminearum from the plated rachis fragments of the lower portion of another spike. 
The variability found in the severity of the symptoms induced in wheat spikes $(F=7.34, P<0.01)$ and in the TKW relative to the uninoculated control $(F=5.31, P<0.01)$ among the 14 isolates reflected the differences previously found for 112 isolates, as did the percentage of inoculated spikes showing symptoms of premature bleaching $(30 \%)$. Similarly, a close correlation was found between FHB severity and the relative TKW ( $r=$ $-0.900, P<0.01)$.

The heritability of symptom severity for the subsample was $H^{2}=0.96$; hence, very similar to the value found for the full sample. This result suggests that the greatest part of the variability found was the result of genotypic differences between the isolates rather than a consequence of the effect of the year of testing.

The results obtained in both years of field tests for severity, reduction of TKW, mycotoxin production, and colonization of the rachis were pooled and values are presented in Table 2.

Progression of $F$. graminearum in wheat spikes from the point of inoculation. In $>90 \%$ of the analyzed rachis, the presence of $F$. graminearum was found colonizing the fragments of the rachis that supported the inoculated spikelets in the field tests $(+0$ and -0$)$ (Figs. 2 and 3). Isolates differed significantly in their ability to colonize these fragments $(F=7.22, P<0.01)$, with values that ranged from 48 to $86 \%$ of the total fragments for isolate MR18 and isolates BA14 and SP1, respectively (Table 2).

For all the treatments and all the spikelet/supporting fragment pairs, the percentage of the presence of the pathogen in the rachis was higher than the percentage of symptomatic spikes in field tests (Fig. 2). The percentage of colonization that resulted was even higher than the percentage of spikes showing symptoms of premature bleaching for all of the spikelet-rachis fragment pairs, except for the most distal position (+6).

Even when no inoculated spike showed FHB symptoms above the +3 spikelet, $F$. graminearum was found colonizing the apical fragment of the rachis in $>25 \%$ of the considered spikes.

The tendency of the distribution of FHB symptoms prevalently downward from the PI observed in the field tests was also verified when the expansion of $F$. graminearum was analyzed (Fig. 3). The higher percentages of colonization were found for the portions corresponding to the inoculated spikelets, disregarding their relative position $(-0$ and +0$)$. No significant differences were found between these portions and those located immediately above $(+1$ and +2$)$ and below $(-1$ and -2$)$ them. The downward distribution of the pathogen was verified from the +3 and -3 fragments onward, because the fall of the percentage of rachis fragments colonized was much more pronounced upward than downward the PI, with final values of $>75$ and $25 \%$ for the -6 and +6 fragments, respectively (Fig. 3).
The percentage of colonization of the rachis fragments by $F$. graminearum was significantly correlated with the severity of FHB symptoms $(r=0.710, P<0.01)$ and, to a lesser extent, with the relative TKW $(r=-0.641, P<0.05)$.

In vivo and in vitro DON production. Isolates differed in their toxigenic potential (Table 2). Significant differences existed for in vivo DON production when the grains collected from the spikes tested in the field were analyzed by means of ELISA $(F=$ $5.91, P<0.01)$. Toxin production ranged from $4.5 \mathrm{ppm}$ for the isolate MR18 to $31.3 \mathrm{ppm}$ for isolate SP1. Significant differences were also found between isolates for in vitro DON production on sterile rice at $80 \%$ relative humidity $(F=4.33, P<0.01)$. In this case, mycotoxin accumulation values ranged from $126 \mathrm{ppm}$ for isolate MR25 to $373 \mathrm{ppm}$ for isolate MR46 (Table 2).

A close correlation was found between the severity of the symptoms induced by the isolates in the field tests and in vivo DON production $(r=0.907, P<0.01)$, as well as between pathogen colonization of the rachis and DON accumulation in the grains $(r=0.808, P<0.01)$. In vitro DON production and severity, on the other hand, were not significantly correlated $(r=$ 0.313 ), and neither were colonization of the rachis and DON production in rice substrate $(r=0.483)$ or toxin accumulation in vivo and in vitro $(r=0.144)$. The regression analysis showed a linear and positive relation between in vivo DON production and severity of FHB symptoms $\left(R^{2}=0.57\right)$ (Fig. 4).

\section{DISCUSSION}

Differences in toxicity between DON and NIV $(11,12)$ make the accurate determination of the chemotypes of $F$. graminearum found in different cropping areas of the world an important factor for the prediction of the risks related to the occurrence of mycotoxin contamination in food and feed.

In Argentina, controversy exists regarding the prevalence of F. graminearum chemotypes. Most of the work carried out with Argentinian isolates of the pathogen suggests that the predominant trichothecene is DON $(4,10,34,53,55)$; nonetheless, potential for NIV contamination could be present $(18,21,33)$.

Here, we analyzed 112 isolates of $F$. graminearum obtained from 28 localities of the Buenos Aires Province in Argentina (35) to determine their chemotype. All tested isolates were characterized as 15-ADON producers based on the amplification of specific fragments of two trichothecene core genes using multiplex PCR $(58,63)$. Our finding agrees with previous reports on the prevalence of the DON chemotype in populations of the pathogen from wheat in Argentina $(4,10,34,53,55)$. In maize, on the other hand, Sampietro et al. (57) reported an important presence of isolates belonging to the NIV chemotype, which the authors

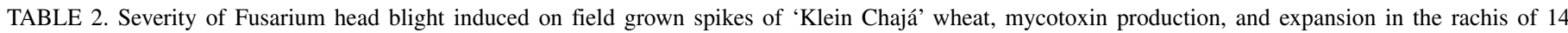
isolates of Fusarium graminearum from Buenos Aires province, Argentina ${ }^{\mathrm{z}}$

\begin{tabular}{|c|c|c|c|c|c|}
\hline Isolate & Severity 21 dpi (\%) & TKW (\% of control) & DON in vivo (ppm) & DON in vitro (ppm) & Spike infection $(\%)$ \\
\hline SP1 & $50 \mathrm{a}$ & $65 \mathrm{c}$ & $31.3 \mathrm{a}$ & $227.8 \mathrm{abc}$ & $86 \mathrm{a}$ \\
\hline LF2 & $35 \mathrm{~b}$ & $70 \mathrm{abc}$ & $16.2 \mathrm{bc}$ & $221.9 \mathrm{abc}$ & 69 abcd \\
\hline BA15 & $28 \mathrm{~b}$ & $79 \mathrm{ab}$ & $19.1 \mathrm{ab}$ & $316.9 \mathrm{abc}$ & $83 a b$ \\
\hline BA14 & $27 \mathrm{~b}$ & $82 \mathrm{ab}$ & $21.2 \mathrm{ab}$ & $238.2 \mathrm{abc}$ & $86 \mathrm{a}$ \\
\hline LH11 & $26 \mathrm{~b}$ & $75 \mathrm{abc}$ & $21.4 \mathrm{ab}$ & $366.7 \mathrm{a}$ & $78 \mathrm{abc}$ \\
\hline 30A3 & $25 \mathrm{bc}$ & $91 \mathrm{ab}$ & $14.3 \mathrm{bc}$ & $328.3 \mathrm{abc}$ & 69 abcd \\
\hline LF1 & $25 \mathrm{bc}$ & $86 \mathrm{ab}$ & $16.2 \mathrm{bc}$ & $316.9 \mathrm{abc}$ & $77 \mathrm{abc}$ \\
\hline MR46 & $23 \mathrm{bc}$ & $80 \mathrm{ab}$ & $14.8 \mathrm{bc}$ & $373.0 \mathrm{a}$ & $81 \mathrm{abc}$ \\
\hline LH7 & $22 \mathrm{bcd}$ & $84 \mathrm{ab}$ & $14.7 \mathrm{bc}$ & $311.0 \mathrm{abc}$ & $80 \mathrm{abc}$ \\
\hline GA1 & $14 \mathrm{bcd}$ & $90 \mathrm{ab}$ & $13.0 \mathrm{bc}$ & $140.6 \mathrm{bc}$ & $60 \mathrm{bcd}$ \\
\hline MR40 & $14 \mathrm{bcd}$ & $87 \mathrm{ab}$ & $11.9 \mathrm{bc}$ & $357.9 \mathrm{ab}$ & 72 abcd \\
\hline MR25 & $11 \mathrm{bcd}$ & $92 \mathrm{ab}$ & $12.7 \mathrm{bc}$ & $126.5 \mathrm{c}$ & 71 abcd \\
\hline MR4 & $10 \mathrm{~cd}$ & $91 \mathrm{ab}$ & $9.4 \mathrm{bc}$ & $244.7 \mathrm{abc}$ & $57 \mathrm{~cd}$ \\
\hline MR18 & $6 \mathrm{~d}$ & $94 \mathrm{a}$ & $4.5 \mathrm{c}$ & $177.2 \mathrm{abc}$ & $48 \mathrm{~d}$ \\
\hline Control & $0 \mathrm{~d}$ & $100 \mathrm{a}$ & $0.1 \mathrm{c}$ & $0.0 \mathrm{c}$ & $3 \mathrm{e}$ \\
\hline
\end{tabular}

$\mathrm{z}$ TKW $=$ thousand-kernel weight and DON $=$ deoxynivalenol. Different letters correspond to significant differences between treatments $(\alpha=0.05)$. 
attributed to potential differences in the preference for the different hosts. These results suggest that the toxigenic potential present in $F$. graminearum populations from Argentina is complex and that there is a chance for significant variation in the range of mycotoxins that could potentially contaminate food and feeds.

In a previous work, we reported the aggressiveness variation present in 112 isolates of $F$. graminearum obtained from 28 localities of Buenos Aires Province in Argentina following inoculation on field-grown wheat spikes (35). To check the representativeness of a subsample of 14 of these isolates, the same parameters previously analyzed for the complete collection of isolates were taken into consideration. The results obtained indicate that the findings previously reported are also valid for these 14 isolates, and that the subsample chosen is representative of the behavior shown by the complete collection (35).

The present work is the first attempt to analyze and relate both the capacity of $F$. graminearum isolates from Argentina to induce symptoms in field-grown wheat spikes and DON production under both in vitro and in vivo culture conditions. Isolates differed in their ability to produce mycotoxins both in the grains obtained from field-grown wheat spikes (in vivo) and under laboratory conditions on a rice substrate (in vitro). Under field conditions, the amount of DON produced surpassed, in all cases, the $2 \mathrm{ppm}$ tolerance limits for commercialization imposed by the European Union standards (60). In vitro DON production was several-fold greater than in vivo production for all isolates but no correlation was found between these two parameters. Similar results were obtained by Walker et al. (61) when testing DON production under field and laboratory conditions. These results suggest that the potential for mycotoxin production shown by $F$. graminearum under controlled conditions has no correlation with its capacity to produce them in planta.

Unlike previous results obtained with $F$. graminearum isolates from Argentina (5), a close correlation between the severity of the symptoms induced by the isolates in field tests and in vivo DON production is reported here. Furthermore, the regression analysis performed showed a positive linear relation between the severity of FHB and DON accumulation in the grain. These results confirm that the trichothecene contamination of wheat grains is a consequence of the severity of FHB symptoms and agree with those obtained by Mesterházy et al. (40) and Mesterházy (39).

On the other hand, neither the aggressiveness of the isolates nor the relative TKW were correlated with in vitro toxin accumulation. Among the resistance mechanisms present in wheat genotypes toward FHB, types III (resistance to infection of the grain) and IV (tolerance to infection) could be related to the capacity of the host to degrade or tolerate DON (29). Recently, it has been demonstrated that some wheat lines possess the ability to detoxify DON by its glucosylation and that this ability is linked to the quantitative trait locus $Q f h s . n d s u$ - $3 B S$ (31). The presence of these or other detoxification mechanisms in the host and their interaction with aggressiveness and toxigenic capacity of $F$. graminearum isolates could be responsible for the absence of a relationship between in vitro and in vivo DON production.

The colonization of the rachis by $F$. graminearum isolates in inoculated wheat spikes is a variable trait. For all the analyzed treatments and spikelet-rachis portion pairs, the percentage of colonization was higher than the visible FHB symptoms. Furthermore, the tendency observed in the distribution of FHB symptoms in the spike from the PI downward (35) was verified when the colonization of the rachis was considered. These results confirm

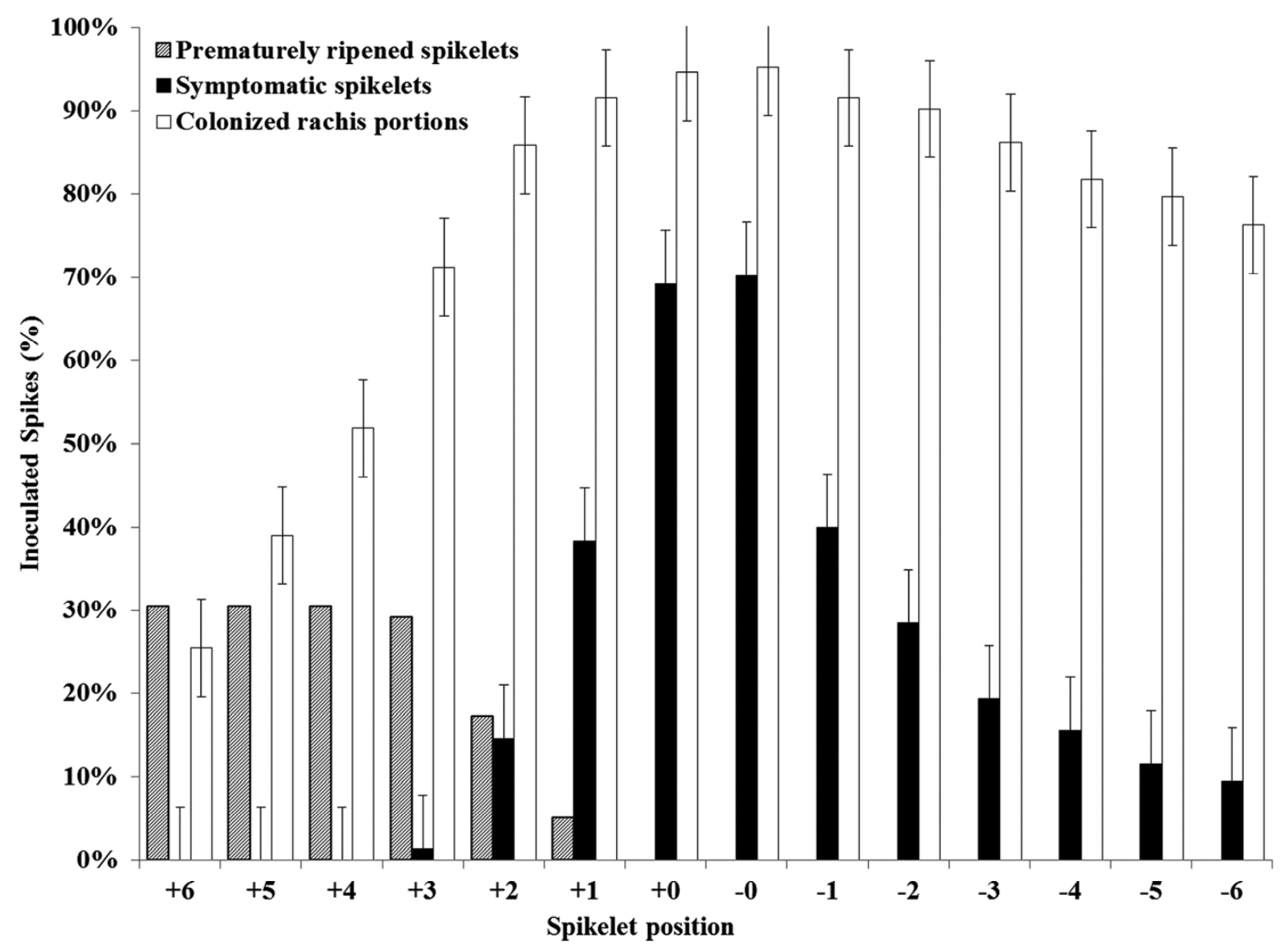

Fig. 2. Percentage of field-grown wheat spikes point-inoculated with each of 14 isolates of Fusarium graminearum showing symptoms of Fusarium head blight, symptoms of premature bleaching, and colonization of rachis fragments by the fungus above and below the point of inoculation (PI). Positive numbers represent the spikelets located above the PI while negative numbers indicate those located below it (i.e., +0 and -0 are the inoculated spikelets and +1 and -1 the spikelets immediately above and below them, respectively). 
that the progress of $F$. graminearum invasion along the spike mainly follows a basipetal route along the vascular tissues and agree with recent reports (9). Differences in connection between the vascular bundle and the rachis of point-inoculated wheat spikelets above and below the PI have been suggested as the cause of the slower acropetal movement of the pathogen in the spike (9).

Rachis colonization was closely correlated with the severity of FHB symptoms and, to a lesser extent, with the relative TKW. Furthermore, colonization was highly correlated with the amount of DON present in wheat grains but not with DON production in vitro. These results agree with those reported by Gilbert et al. (20), who found no correlation between severity of FHB, fungal biomass, and in vitro DON production.

In $>90 \%$ of the total evaluated spikes, the presence of the pathogen could be verified in the rachis portions that corresponded to the inoculated spikelets of the field-grown spikes.
Such percentage exceeded the $70 \%$ incidence observed when visible symptoms of the disease were analyzed in the field (35). According to these results, in a high proportion of inoculated spikes, the simple presence of $F$. graminearum infecting the rachis was not sufficient for the development of FHB symptoms. In this regard, Brown et al. (9) found evidence of a macroscopically asymptomatic stage in wheat spikes where FHB symptoms remained confined to point-inoculated spikelets though, at the cellular level, internal infection by $F$. graminearum was clearly visible.

The colonization of the rachis of asymptomatic spikes by the pathogen could explain the fact that, for isolates that induced the expression of FHB symptoms in extremely low severity values, DON levels detected in the harvested grain were often higher than those tolerated by commercialization standards. These results imply that even isolates with a limited capacity of induction of visible symptoms of FHB and reduction of TKW may be able to

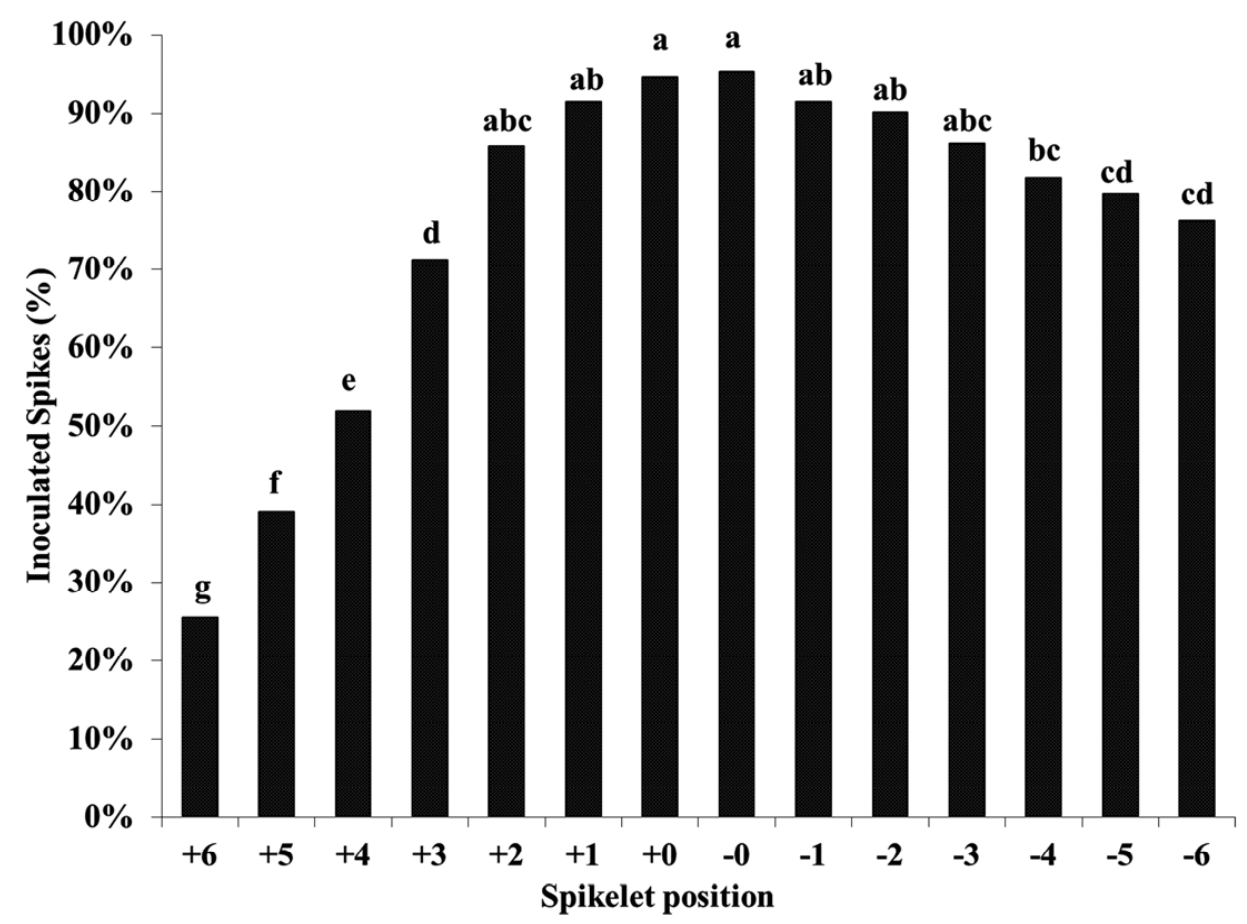

Fig. 3. Percentage of field-grown wheat spikes point inoculated with 14 isolates of Fusarium graminearum with rachis portions above and below the point of inoculation (PI) showing colonization by the fungus. Positive numbers represent the spikelets located above the PI while negative numbers indicate those located below it (i.e., +0 and -0 are the inoculated spikelets and +1 and -1 the spikelets immediately above and below them, respectively). Different letters indicate the existence of significant differences between treatments $(\alpha=0.05)$.

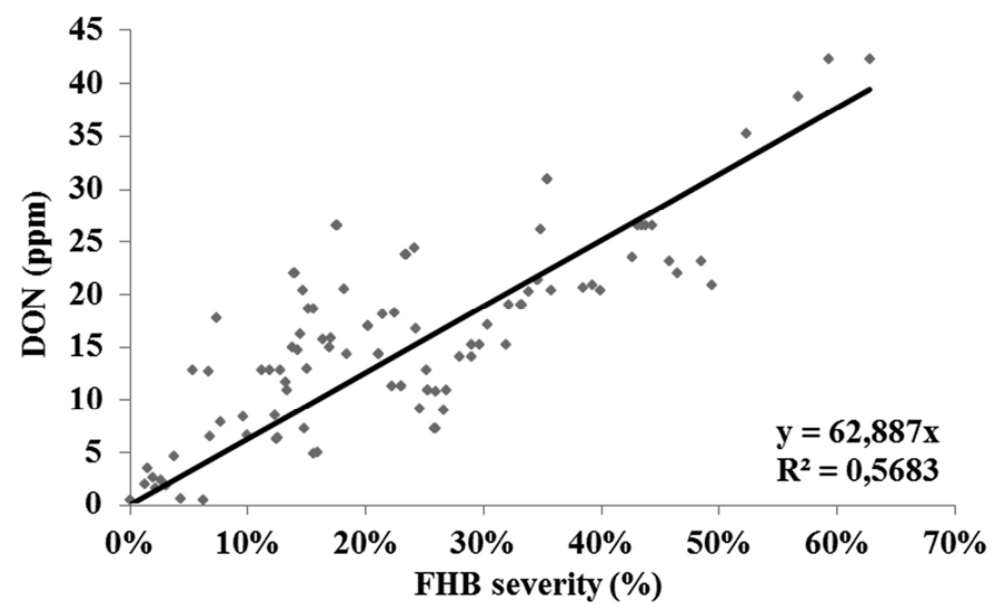

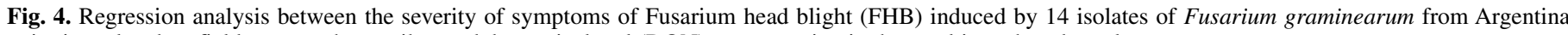
point inoculated on field-grown wheat spikes and deoxynivalenol (DON) concentration in the resulting wheat kernels. 
colonize the rachis of wheat spikes, producing detectable amounts of DON.

The search for wheat genotypes tolerant or resistant to FHB, which could aid in lowering the impact of mycotoxin contamination of food and feed, constitutes a fundamental objective for breeders. The results obtained in our work allow hypothesizing that limiting the exposition of wheat genotypes to DON as well as increasing the tolerance of the plant to trichothecenes could reduce the development of $F$. graminearum and, as a consequence, diminish the severity of FHB attacks. Recently, we reported that the presence of high levels of variability among the populations of $F$. graminearum prompted the need to include mixtures of isolates when screening for disease-resistant genotypes (35). According to the results reported in the present work, the fact that even isolates with limited aggressiveness present an important risk of DON contamination emphasizes the need to use combinations of isolates that reflect not only the variable levels of aggressiveness but also the variability in toxigenic potential present in the populations of the pathogen.

\section{ACKNOWLEDGMENTS}

I. Malbrán and C. A. Mourelos are grant holders and J. R. Girotti is a member of the Consejo Nacional de Investigaciones Científicas y Técnicas (CONICET). P. A. Balatti and G. A. Lori are members of the Comisión de Investigaciones Científicas de la Provincia de Buenos Aires (CICBA). This study was supported by CICBA and projects PICT 25479 and PICT-PAE 37046-77/07 from the Agencia Nacional de Promoción Científica y Técnica (ANPCyT). We thank Q. Migheli for his careful and critical reading of the manuscript.

\section{LITERATURE CITED}

1. Adams, G. C., and Hart, L. P. 1989. The role of deoxynivalenol and 15acetyldeoxynivalenol in pathogenesis by Gibberella zeae, as elucidated through protoplast fusions between toxigenic and nontoxigenic strains. Phytopathology 79:404-408.

2. Alexander, N. J., McCormick, S. P., Waalwijk, C., van der Lee, T., and Proctor, R. H. 2011. The genetic basis for 3-ADON and 15-ADON trichothecene chemotypes in Fusarium. Fungal Genet. Biol. 48:495-485.

3. Alexander, N. J., Proctor, R. H., and McCormick, S. P. 2009. Genes, gene clusters, and biosynthesis of trichothecenes and fumonisins in Fusarium. Toxin Rev. 28:198-215.

4. Alvarez, C. L., Azcarate, M. P., and Pinto, V. F. 2009. Toxigenic potential of Fusarium graminearum sensu stricto isolates from wheat in Argentina. Int. J. Food Microbiol. 135:131-135.

5. Alvarez, C. L., Somma, S., Moretti, A., and Fernández Pinto, V. 2010. Aggressiveness of Fusarium graminearum sensu stricto isolates in wheat kernels in Argentina. J. Phytopathol. 158:173-181.

6. Arseniuk, E., Foremska, E., Goral, T., and Chelkowski, J. 1999. Fusarium head blight reactions and accumulation of deoxynivalenol (DON) and some of its derivatives in kernels of wheat, triticale and rye. J. Phytopathol. 147:577-590.

7. Astolfi, P., Reynoso, M. M., Ramirez, M. L., Chulze, S. N., Alves, T. C. A., Tessmann, D. J., and Del Ponte, E. M. 2012. Genetic population structure and trichothecene genotypes of Fusarium graminearum isolated from wheat in southern Brazil. Plant Pathol. 61:289-295.

8. Brown, D. W., Dyer, R. B., McCormick, S. P., Kendra, D. F., and Plattner, R. D. 2004. Functional demarcation of the Fusarium core trichothecene gene cluster. Fungal Genet. Biol. 41:454-462.

9. Brown, N. A., Urban, M., van de Meene, A. M. L., and HammondKosack, K. E. 2010. The infection biology of Fusarium graminearum: defining the pathways of spikelet to spikelet colonisation in wheat ears. Fungal Biol. 114:555-571.

10. Dalcero, A., Torres, A. M., Etcheverry, M., Chulze, S., and Varsavsky, E. 1997. Occurrence of deoxynivalenol and Fusarium graminearum in Argentinian wheat. Food Addit. Contam. 14:11-14.

11. Desjardins, A. E. 2006. Fusarium Mycotoxins: Chemistry, Genetics, and Biology. American Phytopathological Society Press, St. Paul, MN.

12. Desjardins, A. E., and Proctor, R. H. 2007. Molecular biology of Fusarium mycotoxins. Int. J. Food Microbiol. 119:47-50.

13. Desjardins, A. E., Proctor, R. H., Bai, G. H., McCormick, S. P., Shaner, G., Buechley, G., and Hohn, T. M. 1996. Reduced virulence of trichothecene-nonproducing mutants of Gibberella zeae in wheat field tests. Mol. Plant-Microbe Interact. 9:775-781.
14. Desmond, O. J., Manners, J. M., Stephens, A. E., Maclean, D. J., Schenk, P. M., Gardiner, D. M., Munn, A. L., and Kazan, K. 2008. The Fusarium mycotoxin deoxynivalenol elicits hydrogen peroxide production, programmed cell death and defence responses in wheat. Mol. Plant Pathol. 9:435-445.

15. Dubin, H. J., Gilchrist, L., Reeves, J., and McNab, A. 1997. Fusarium Head Scab: Global Status and Future Prospects. H. J. Dubin, L. Gilchrist, J. Reeves, and A. McNab, eds. CIMMYT (Int. Maize and Wheat Improvement Center), Mexico D.F., Mexico.

16. Faifer, G. C., Sala De Miguel, M., and Godoy, H. M. 1990. Patterns of mycotoxin production by Fusarium graminearum isolated from Argentine wheat. Mycopathologia 109:165-170.

17. Fehr, W. R. 1987. Principles of Cultivar Development. Theory and Technique, Vol. 1. Macmillan Publishing Co., New York.

18. Fernández Pinto, V., Terminiello, L. A., Basilico, J. C., and Ritieni, A. 2008. Natural occurrence of nivalenol and mycotoxigenic potential of Fusarium graminearum strains in wheat affected by head blight in Argentina. Braz. J. Microbiol. 39:157-162.

19. Galich, M. T. V. De. 1997. Fusarium head blight in Argentina. Pages 1928 in: Fusarium Head Scab: Global Status and Future Prospects. H. J. Dubin, L. Gilchrist, J. Reeves, and A. McNab, eds. CIMMYT (Int. Maize and Wheat Improvement Center), Mexico D.F., Mexico.

20. Gilbert, J., Abramson, D., McCallum, B. D., and Clear, R. 2002. Comparison of Canadian Fusarium graminearum isolates for aggressiveness, vegetative compatibility, and production of ergosterol and mycotoxins. Mycopathologia 153:209-215.

21. González, H. H. L., Moltó, G., Pacin, A., Resnik, S., Zelaya, M., Masana, M., and Martínez, E. J. 2008. Trichothecenes and mycoflora in wheat harvested in nine locations in Buenos Aires Province, Argentina. Mycopathologia 165:105-114

22. Gosman, N. E., Bayles, R., Jennings, P., Kirby, J., and Nicholson, P. 2007. Evaluation and characterization of resistance to Fusarium head blight caused by Fusarium culmorum in UK winter wheat cultivars. Plant Pathol. 56:264-276.

23. Gosman, N. E., Chandler, E., Thomsett, M., Draeger, R., and Nicholson, P. 2005. Analysis of the relationship between parameters of resistance to Fusarium head blight and in vitro tolerance to deoxynivalenol of the winter wheat cultivar WEK0609. Eur. J. Plant Pathol. 111:57-66.

24. Ichinoe, M., Kurata, H., Sugiura, Y., and Ueno, Y. 1983. Chemotaxonomy of Gibberella zeae with special reference to production of trichothecenes and zearalenone. Appl. Environ. Microbiol. 46:1364-1369.

25. Jansen, C., von Wettstein, D., Schäfer, W., Kogel, K.-H., Felk, A., and Maier, F. J. 2005. Infection patterns in barley and wheat spikes inoculated with wild-type and trichodiene synthase gene disrupted Fusarium graminearum. Proc. Natl. Acad. Sci. USA 102:16892-16897.

26. Jennings, P., Coates, M. E., Walsh, K., Turner, J. A., and Nicholson, P. 2004. Determination of deoxynivalenol- and nivalenol-producing chemotypes of Fusarium graminearum isolated from wheat crops in England and Wales. Plant Pathol. 53:643-652.

27. Kendrick, B. 1992. Mycotoxins in food and feeds. Pages 316-331 in: The Fifth Kingdom. Focus Texts, Newburyport, MA.

28. Kikot, G. E., Moschini, R. C., Consolo, V. F., Rojo, R., Salerno, G., Hours, R. A., Gasoni, L., Arambarri, A. M., and Alconada, T. M. 2011. Occurrence of different species of Fusarium from wheat in relation to disease levels predicted by a weather-based model in Argentina Pampas Region. Mycopathologia 171:139-149.

29. Langevin, F., Eudes, F., and Comeau, A. 2004. Effect of trichothecenes produced by Fusarium graminearum during Fusarium head blight development in six cereal species. Eur. J. Plant Pathol. 110:735-746.

30. Lee, T., Han, Y., Kim, K., and Yun, S. 2002. Tri13 and Tri7 determine deoxynivalenol-and nivalenol-producing chemotypes of Gibberella zeae. Appl. Environ. Microbiol. 68:2148-2154.

31. Lemmens, M., Scholz, U., Berthiller, F., Dall'Asta, C., Koutnik, A., Schuhmacher, R., Adam, G., Buerstmayr, H., Mesterházy, A., Krska, R., and Ruckenbauer, P. 2005. The ability to detoxify the mycotoxin deoxynivalenol colocalizes with a major quantitative trait locus for Fusarium head blight resistance in wheat. Mol. Plant-Microbe Interact. 18:1318-1324.

32. Liu, W., Langseth, W., Elen, O. N., and Sundheim, L. 1997. Comparison of visual head blight ratings, seed infection levels, and deoxynivalenol production for assessment of resistance in cereals inoculated with Fusarium. Eur. J. Plant Pathol. 103:589-595.

33. Lori, G. A., Carranza, M. R., Violante, A., Rizzo, I., and Alippi, H. E. 1992. Fusarium spp. en trigo, capacidad toxicogénica y quimiotaxonomía de las cepas aisladas en la Argentina. Agronomie 12:459-467.

34. Lori, G. A., Sisterna, M. N., Haidukowski, M., and Rizzo, I. 2003. Fusarium graminearum and deoxynivalenol contamination in the durum wheat area of Argentina. Microbiol. Res. 158:29-35.

35. Malbrán, I., Mourelos, C. A., Girotti, J. R., Aulicino, M. B., Balatti, P. A., and Lori, G. A. 2012. Aggressiveness variation of Fusarium graminearum 
isolates from Argentina following point inoculation of field grown wheat spikes. Crop Prot. 42:234-243.

36. McCormick, S. P. 2003. The role of DON in pathogenicity. Pages 165-183 in: Fusarium Head Blight of Wheat and Barley. K. J. Leonard and W. R. Bushnell, eds. The American Phytopathological Society Press, St. Paul, MN.

37. McIntosh, M. S. 1983. Analysis of combined experiments. Agron. J. 75:153-155.

38. McMullen, M. P., Jones, R., and Gallenberg, D. 1997. Scab of wheat and barley: a re-emerging disease of devastating impact. Plant Dis. 81:13401348.

39. Mesterházy, Á. 2002. Role of deoxynivalenol in aggressiveness of Fusarium graminearum and F. culmorum and in resistance to Fusarium head blight. Eur. J. Plant Pathol. 108:675-684.

40. Mesterházy, Á., Bartók, T., Mirocha, C. G., and Komoróczy, R. 1999. Nature of wheat resistance to Fusarium head blight and the role of deoxynivalenol for breeding. Plant Breed.118:97-110.

41. Miedaner, T., Reinbrecht, C., and Schilling, A. G. 2000. Association among aggressiveness, fungal colonization, and mycotoxin production of 26 isolates of Fusarium graminearum in winter rye head blight. Z. Pflanzenkrankh. Pflanzenschutz 107:124-134.

42. Miller, J. D., ApSimon, J. W., Blackwell, B. A., Greenhalgh, R., and Taylor, A. 2001. Deoxynivalenol: a 25 year perspective on a trichothecene of agricultural importance. Pages 310-320 in: Fusarium Paul E. Nelson Memorial Symposium. B. A. Summerell, J. F. Leslie, D. Backhouse, W. L. Bryden, and L. W. Burgess, eds. The American Phytopathological Society Press, St. Paul, MN.

43. Moschini, R. C., and Fortugno, C. 1996. Predicting wheat head blight incidence using models based on meteorological factors in Pergamino, Argentina. Eur. J. Plant Pathol. 102:211-218.

44. Moss, M. O., and Thrane, U. 2004. Fusarium taxonomy with relation to trichothecene formation. Toxicol. Lett.153:23-28.

45. Nishiuchi, T., Masuda, D., Nakashita, H., Ichimura, K., Shinozaki, K., Yoshida, S., Kimura, M., Yamaguchi, I., and Yamaguchi, K. 2006. Fusarium phytotoxin trichothecenes have an elicitor-like activity in Arabidopsis thaliana, but the activity differed significantly among their molecular species. Mol. Plant-Microbe Interact. 19:512-520.

46. Pan, D., Calero, N., Mionetto, A., and Bettucci, L. 2013. Trichothecene genotypes of Fusarium graminearum from wheat in Uruguay. Int. J. Food Microbiol. 162:120-123.

47. Pasquali, M., Giraud, F., Brochot, C., Cocco, E., Hoffmann, L., and Bohn, T. 2010. Genetic Fusarium chemotyping as a useful tool for predicting nivalenol contamination in winter wheat. Int. J. Food Microbiol. 137:246253.

48. Proctor, R. H., Desjardins, A. E., McCormick, S. P., Plattner, R., Alexander, N. J., and Brown, D. W. 2002. Genetic analysis of the role of trichothecene and fumonisin mycotoxins in the virulence of Fusarium. Eur. J. Plant Pathol. 108:691-698.

49. Proctor, R. H., Hohn, T. M., and McCormick, S. P. 1995. Reduced virulence of Gibberella zeae caused by disruption of a trichothecene toxin biosynthetic gene. Mol. Plant-Microbe Interact. 8:593-601.

50. Proctor, R. H., Hohn, T. M., and McCormick, S. P. 1997. Restoration of wild-type virulence to Tri5 disruption mutants of Gibberella zeae via gene reversion and mutant complementation. Microbiology 143:2583-2591.
51. Prodi, A., Tonti, S., Nipoti, P., Pancaldi, D., and Pisi, A. 2009. Identification of deoxynivalenol and nivalenol producing chemotypes of Fusarium graminearum isolates from durum wheat in a restricted area of northern Italy. J. Plant Pathol. 91:727-731.

52. Puri, K. D., and Zhong, S. 2010. The 3ADON population of Fusarium graminearum found in North Dakota is more aggressive and produces a higher level of DON than the prevalent 15ADON population in spring wheat. Phytopathology 100:1007-1014.

53. Ramírez, M. L., Chulze, S. N., and Magan, N. 2006. Temperature and water activity effects on growth and temporal deoxynivalenol production by two Argentinean strains of Fusarium graminearum on irradiated wheat grain. Int. J. Food Microbiol. 106:291-296.

54. Ramírez, M. L., Reynoso, M. M., Farnochi, M. C., and Chulze, S. N. 2006. Vegetative compatibility and mycotoxin chemotypes among Fusarium graminearum (Gibberella zeae) isolates from wheat in Argentina. Eur. J. Plant Pathol. 115:139-148.

55. Reynoso, M. M., Ramírez, M. L., Torres, A. M., and Chulze, S. N. 2011. Trichothecene genotypes and chemotypes in Fusarium graminearum strains isolated from wheat in Argentina. Int. J. Food Microbiol. 145:444 448.

56. Rocha, O., Ansari, K., and Doohan, F. M. 2005. Effects of trichothecene mycotoxins on eukaryotic cells: a review. Food Addit. Contam. 22:369378

57. Sampietro, D. A., Díaz, C. G., Gonzalez, V., Vattuone, M. A., Ploper, L. D., Catalan, C. A. N., and Ward, T. J. 2011. Species diversity and toxigenic potential of Fusarium graminearum complex isolates from maize fields in northwest Argentina. Int. J. Food Microbiol. 145:359-364.

58. Starkey, D. E., Ward, T. J., Aoki, T., Gale, L. R., Kistler, H. C., Geiser, D. M., Suga, H., Tóth, B., Varga, J., and O’Donnell, K. 2007. Global molecular surveillance reveals novel Fusarium head blight species and trichothecene toxin diversity. Fungal Genet. Biol. 44:1191-1204.

59. Suga, H., Karugia, G. W., Ward, T. J., Gale, L. R., Tomimura, K., Nakajima, T., Miyasaka, A., Koizumi, S., Kageyama, K., and Hyakumachi, M. 2008. Molecular characterization of the Fusarium graminearum species complex in Japan. Phytopathology 98:159-166.

60. Van Egmond, H. P., Schothorst, R. C., and Jonker, M. A. 2007. Regulations relating to mycotoxins in food: perspectives in a global and European context. Anal. Bioanal. Chem. 389:147-157.

61. Walker, S. L., Leath, S., Hagler, W. M., and Murphy, J. P. 2001. Variation among isolates of Fusarium graminearum associated with Fusarium head blight in North Carolina. Plant Dis. 85:404-410.

62. Wang, H., Hwang, S., Eudes, F., Chang, K., Howard, J., and Turnbull, G. 2006. Trichothecenes and aggressiveness of Fusarium graminearum causing seedling blight and root rot in cereals. Plant Pathol. 55:224-230.

63. Ward, T. J., Bielawski, J. P., Kistler, H. C., Sullivan, E., and O'Donnell, K. 2002. Ancestral polymorphism and adaptive evolution in the trichothecene mycotoxin gene cluster of phytopathogenic Fusarium. Proc. Natl. Acad. Sci. USA 99:9278-9283.

64. Zadoks, J. C., Chang, T. T., and Konzak, C. F. 1974. A decimal code for the growth stages of cereals. Weed Res. 14:415-421.

65. Zhang, H., Van der Lee, T., Waalwijk, C., Chen, W., Xu, J., Xu, J., Xu, J., Zhang, Y., and Feng, J. 2012. Population analysis of the Fusarium graminearum species complex from wheat in China show a shift to more aggressive isolates. PloS One 7:e31722. 